\title{
EDITORIAL
}

\section{The Maturing of Transnational Environmental Law}

\section{INTRODUCTION}

Just over five years ago, the first issue of Transnational Environmental Law (TEL) was published. At the time, a sense of cautious optimism imbued environmental law and policymaking efforts. There was hope for a new and improved climate change regime; hope for renewed United States (US) leadership on all matters environmental; hope for strong European Union (EU) leadership on multilateral environmental issues, such as climate change and chemical regulation; hope that market-based mechanisms could provide effective tools for advancing sustainable development; and hope that emerging forms of new governance would fill gaps left by incomplete or fragmented systems of domestic and international law. Against this backdrop of growth and evolution, TEL provided a singular platform for exploring the emerging field of transnational environmental law. Early contributions unpacked the concept of transnational environmental law, ${ }^{1}$ explored the challenges underlying the rise of transnational environmental law, ${ }^{2}$ and began the process of looking at particular transnational environmental challenges in context. ${ }^{3}$

Today, the terrain of environmental law and policy is dramatically different. Both the US and the EU have suffered significant political shocks with, at least in the case of the US, potentially devastating environmental consequences. The 2015 Paris Agreement on climate change ${ }^{4}$ holds out hope for global cooperation and experimentation, but the world is already living a reality of increasingly dire climate predictions and slower than needed climate change limiting efforts. Market-based mechanisms continue to dot the terrain but their use remains plagued with challenges of effectiveness ${ }^{5}$ and equity. Amidst

1 G. Shaffer \& D. Bodansky, 'Transnationalism, Unilateralism and International Law' (2012) 1(1) Transnational Environmental Law, pp. 31-41.

2 E. Fisher, 'The Rise of Transnational Environmental Law and the Expertise of Environmental Lawyers' (2012) 1(1) Transnational Environmental Law, pp. 43-52.

3 E. Brown Weiss, 'The Coming Water Crisis: A Common Concern of Humankind' (2012) 1(1) Transnational Environmental Law, pp. 153-69.

4 Paris (France), 13 Dec. 2015, in force 4 Nov. 2016, UNFCCC Secretariat, Decision 1/CP.21 'Adoption of the Paris Agreement', UN Doc. FCCC/CP/2015/10/Add.1, Annex, available at: http://unfccc.int/ resource/docs/2015/cop21/eng/10a01.pdf.

5 E.g., M. Wara, 'Measuring the Clean Development Mechanism's Performance and Potential' (2008) 55(6) UCLA Law Review, pp. 1759-803. 
this change, the transnationalization of environmental law has remained a constant. From the growth of private environmental governance systems, ${ }^{6}$ to the rise of hybrid forms of governance underpinning areas such as climate finance, adaptation, technology transfer, and land-use change and forestry, ${ }^{7}$ to the continued importance of the EU as an environmental governance regime, with the accompanying spin-off challenges and developments, ${ }^{8}$ the most persistent trend in environmental law has been the diversification of tools and approaches to address environmental challenges and the proliferation of regulation beyond the state'.

In 2012, TEL carved out a space to facilitate more focused and intentional conversations about the meaning, shape, evolution, and implication of transnational environmental law. Five years on, the nature and depth of that conversation has evolved and become increasingly central to efforts to combat a growing set of global environmental challenges. As our understanding of the complexity of environmental processes such as climate change and biodiversity loss has deepened, and recognition of the inadequacy of traditional forms of governance to address many contemporary environmental challenges has become more pervasive, the conversations around what law is, and what forms of law and governance are available to address an increasingly complex and interlinked set of systemic environmental challenges has progressed at a rapid pace. ${ }^{10}$ In this more cosmopolitan space, ${ }^{11}$ TEL continues to serve as a critical outlet for increasingly sophisticated analyses of the range of theoretical and practical questions inherent in the process of moving towards a more effective and just system of transnational environmental law.

The diverse collection of articles in this issue focuses on the challenges associated with the transnationalization of environmental law. The first four articles explore questions of this transnationalization at a general and theoretical level. They evaluate the transformative impact of transnational environmental regulation on law; weigh the merits of using 'macro' legal analysis to improve understanding of systems of global environmental governance (GEG); examine the role of systems of private authority in complex regimes; and consider the availability of domestic tort mechanisms for addressing extraterritorial environmental pollution.

The second set of contributions to this issue of TEL illustrates the diversity of challenges that accompany transnationalization in a more case-specific context. With topics ranging from the use of market-based instruments for biodiversity protection in

6 J.F. Green \& G. Auld, 'Unbundling the Regime Complex: The Effects of Private Authority' (2017) 6(2) Transnational Environmental Law, pp. 259-84.

7 For a more overarching examination of the evolution of climate governance, see K.W. Abbott, 'Strengthening the Transnational Regime Complex for Climate Change' (2014) 3(1) Transnational Environmental Law, pp. 57-88.

8 M. Hedemann-Robinson, 'Environmental Inspections and the EU: Securing an Effective Role for a Supranational Union Legal Framework' (2017) 6(1) Transnational Environmental Law, pp. 31-58.

9 V. Heyvaert, 'The Transnationalization of Law: Rethinking Law through Transnational Environmental Regulation' (2017) 6(2) Transnational Environmental Law, pp. 205-36, at 206.

10 E.g., see the planetary boundaries and earth system literature: F. Biermann, Earth System Governance: World Politics in the Anthropocene (The MIT Press, 2014); J. Rockström et al., 'A Safe Operating Space for Humanity' (2009) 461(7263) Nature, pp. 472-5.

11 M. Koskenniemi, The Politics of International Law (Hart, 2011). 
developing countries to the impact of linking emissions trading regimes on taxation and, finally, the conservation of small cetaceans, each contribution highlights yet another facet of the kaleidoscope of legal problems and opportunities through which our understanding of transnational environmental law is constantly being fine-tuned and reconfigured.

\section{SHARPENING THE LENS ON THE EVOLVING SYSTEM OF TRANSNATIONAL ENVIRONMENTAL LAW}

In her contribution, Veerle Heyvaert provides one of the most detailed and thoughtful analyses to date of the transformative impacts that the rise of transnational regulation has on how we understand and rely on systems of law. Focusing on the field of transnational environmental regulation (TER), she carefully shows the extent to which the growth and diversification of transnational environmental regulation challenge 'the continued appropriateness of representations of law' along traditional lines, including understanding law as territorial, emanating from the state, composed of a public and private sphere, being constitutive and regulatory in function, and cohesive and regimented. ${ }^{12}$ Instead, Heyvaert argues, the transnationalization of law requires us to rethink fundamentally how law is perceived, suggesting in key part that law is increasingly understood as delocalized, flowing from a plurality of sources, organizationally inchoate, reflexive and coordinating in function, and polycentric. ${ }^{13}$

Heyvaert begins her unravelling of the 'Pandora's box of conceptual dilemmas, uncertainties and transitional problems' ${ }^{14}$ that the transnationalization of law creates, by offering much needed definitional clarity. Definitional imprecision is a constant challenge in the field of environmental law, where terms as varied as 'regulation', 'governance', and 'sustainable development' are often employed with little care for unpacking their meaning and the normative and practical implications of using the terms in particular ways. Heyvaert carefully explores different approaches to defining regulation and distinguishing regulation and governance, and regulation and law, and offers both her preferred definitions and understandings of these relationships and reasons why she adopts the approach that she does. Heyvaert's recognition that 'the proliferation of TER creates a number of acute definitional dilemmas', ${ }^{15}$ and her engagement with these preliminary definitional questions, create a solid platform for unravelling how the transnationalization of law shapes our understanding of regulation, governance, and law.

Heyvaert then launches into a meticulously structured analysis of how TER is impacting upon traditional conceptualizations of law before exploring a series of possible responses to the transnationalization of law and suggesting the strengths and weaknesses of each potential response. Guided by the concise declaration that

12 Heyvaert, n. 9 above, pp. 205-6.

13 Ibid.

14 Ibid., p. 222.

15 Ibid., p. 207. 
' $\left[\mathrm{t}\right.$ ]ransnational environmental regulatory initiatives cause legal complexity', ${ }^{16}$ Heyvaert uses a brief case study to demonstrate how even relatively simple systems of TER destabilize conventional understandings of law and legal governance and create layers of questions concerning the compatibility and complementarity of TER and traditional notions of law. As she notes, not only does TER disrupt traditional notions of legal governance, but it often also 'produces behaviour that is at least in part regulatory' and 'creates an intricate legal context'. ${ }^{17}$ In this way, ' $[\mathrm{t}]$ ransnational, decentred regulation ... co-produces transnational, decentred law. Moreover, this transnationalization of law calls into question the usefulness of many of the attributes that conventionally serve to distinguish law from non-law'. ${ }^{18}$

Once Heyvaert has set the scene for the disruptive nature of TER, she maps the impacts along a number of lines, focusing on how TER affects our understanding of 'the location, the sources, the organization, the functions, and the structure of law'. ${ }^{19}$ After deconstructing the façade of conventional legal governance, she offers a range of potential responses, sorted into three categories. Firstly, there are 'responses that aim to reclaim law as conventionally conceived' - defensive responses that seek to assign systems of TER to pre-existing categories rather than to view and engage with the challenges and tensions TER creates for legal governance. ${ }^{20}$ Secondly, there are those who recognize the destabilization of law and embrace adaptive responses, but continue to see the project as one focused on 'reconstruct[ing] law and thereby restor[ing] its conventional attributes and functionalities', as opposed to fully diving into the deconstructed world that TER arguably creates. ${ }^{21}$ Thirdly, there are those that embrace a more inclusive reconceptualization of law that challenges the notion that law was ever as rigid as perceived and, instead, suggests that TER has 'tipped the veil on the artificiality of the incumbent paradigm', allowing for a more pluralistic and inclusive reconceptualization of law. ${ }^{22}$

Ultimately, Heyvaert effectively shows not only how disruptive the transnationalization of law is to our understanding of law, but also how this disruption creates opportunities 'to further our knowledge about law's nature and dynamics, to adapt the cognitive frameworks through which legal processes are perceived and constructed, and to develop a paradigm that is better attuned to the new (or newly revealed) reality of law'. ${ }^{23}$ In this way, transnational law becomes a vehicle for engaging in more transparent conversations around the desired shape and force of law and legal governance structures.

Stephen Turner's contribution similarly explores the consequences of shifting patterns of transnational environmental governance. ${ }^{24}$ However, Turner focuses on

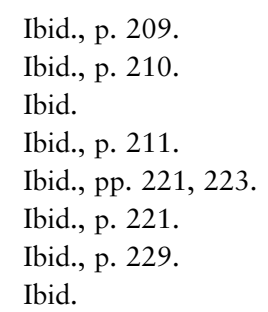

24 S. Turner, 'The Use of "Macro" Legal Analysis in the Understanding and Development of Global Environmental Governance' (2017) 6(2) Transnational Environmental Law, pp. 237-57. 
the narrower question of how to improve understanding and legal analysis of systems of global environmental governance (GEG). Crucially, Turner suggests that existing approaches to legal analysis of GEG are incomplete and overly narrow as they are bound by disciplinary constraints that limit the ability to see how different systems interact. These existing, issue-specific studies of law - what he terms 'micro' legal analysis - create incomplete pictures of the problem, the suitability of the devised solution, and the pool of potential responses. Rather, Turner suggests, we need to adopt a form of 'macro' legal analysis that 'entails the consideration of a range of different areas of law and associated institutions' and helps to build 'a broader understanding of the causes of environmental degradation from a legal standpoint' ${ }^{25}$

Drawing on the rich literature that explores compartmentalization and fragmentation in domestic and international law, Turner unpacks the jurisdictional and disciplinary constraints that challenge efforts to understand and respond adequately to the drivers of environmental change. In doing so, he finds that 'lawyers will naturally tend to approach the subject through the lens of a compartmentalized area of expertise rather than taking into account the full range of component legal disciplines of which it consists'. ${ }^{26}$

Within this compartmentalized and fragmented framework, Turner explores the different roles that non-state actors can play in the development of GEG with an eye to understanding how non-state actors, as increasingly important players in governance, can either reinforce or challenge the compartmentalization of the law. Ultimately, Turner concludes that while it is 'clear that non-state actors play vital roles in the development of GEG ... much of their activity takes place within the compartmentalized components of GEG and, as such, they often reinforce that compartmentalization through their practices and through the "micro" legal analysis that they undertake'. ${ }^{27}$

Having concluded that non-state actors operate largely within the compartmentalized system, Turner offers a series of theoretical arguments for embracing 'macro' legal analysis. Turner justifies the move towards a more comprehensive form of legal analysis with reference to, among others factors, calls for a more cosmopolitan society, a recognition of the need to overcome intellectual blind spots, and parallel moves towards more inclusive, analytical intellectual frameworks in other contexts. He then sets out a methodology for achieving 'macro' legal analysis and encouraging a rethinking of how we train lawyers to undertake legal analysis.

Turner's central argument that 'macro' legal analysis can 'assist in our understanding and development of the legal and quasi-legal components of GEG',28 parallels Heyvaert's underlying premise that our visions of law, regulation, and governance are incomplete, and similarly advocates stepping back and rethinking our conception of law and legal governance systems. Jessica Green and Graeme Auld also

$\begin{array}{ll}25 & \text { Ibid., p. } 242 . \\ 26 & \text { Ibid., p. } 246 . \\ 27 & \text { Ibid., p. } 249 . \\ 28 & \text { Ibid., p. } 256 .\end{array}$ 
aim to improve our knowledge of increasingly complex transnational legal systems. Their contribution centres on the argument that there is a gap in the regime complex literature with respect to private authority and claim that an inadequate comprehension of systems of private authority impedes efforts to understand the functionality of complex regimes. ${ }^{29}$

Private authority, the authors assert, unfolds in 'situations in which non-state actors make rules or set standards, which other actors in world politics adopt' ${ }^{30}$ It 'emerges when there are gaps in public authority ... that is, where governments are unable or choose not to govern'. ${ }^{31}$ In the light of the proliferation of private authority in contemporary environmental governance, Green and Auld explore progress in understanding the interactions within and among complex environmental regimes while simultaneously highlighting how the failure to focus on systems of private authority impedes these efforts.

The authors employ regime-specific examples from the areas of climate change, tropical commodities, and fisheries to show how 'including private authority in the study of regime complexity elucidates previously overlooked types of interaction ... [that] affect the overall design of the regime complex and thereby improve its problem-solving capacity'. ${ }^{32}$ Ultimately, Greene and Auld suggest that the roles played by systems of private authority are varied and complex, and that our understanding of the interaction between private and public authority, and between different systems of private authority, is poor and weakens our grasp of regime complexity.

Together, Heyvaert, Turner, and Green and Auld shed light on the degree to which the transnationalization of systems of environmental law challenges our core conception of law, our ability to discern and respond to the drivers of environmental degradation, and our ability to unravel the complex governance systems that characterize many areas of environmental protection. Read together, these three articles exemplify both the dynamic nature of change in the field of transnational environmental law and the deepening level of scholarly engagement with this transforming field.

While the first three contributions illustrate how processes of transnationalization shape constructs of law and foster the creation of increasingly complex environmental regimes, the contribution by Elena Blanco and Ben Pontin demonstrates that the transnationalization of law also affects domestic law. ${ }^{33}$ The article addresses a more traditional question of jurisdictional boundaries and conflict of laws, as it examines the capacity of the English tort law system to accommodate tort claims which involve extraterritorial harm. Focusing on a nuisance litigation case in the English courts involving the exploitation of oil in the Niger Delta by Shell and its subsidiaries, the authors explore the 'extent to which the Shell litigation helps to

29 Green \& Auld, n. 6 above.

30 Ibid., p. 262.

31 Ibid.

32 Ibid., p. 261.

33 E.M. Blanco \& B. Pontin, 'Litigating Extraterritorial Nuisances under English Common Law and UK Statute' (2017) 6(2) Transnational Environmental Law, pp. 285-308. 
elucidate an alternative ... approach to questions of jurisdiction, ${ }^{34}$ with respect to a type of claim that challenges traditional notions of jurisdiction, but raises important questions of justice and accountability. The authors juxtapose their analysis against similar litigation in the US where, in the case of Kiobel v. Royal Dutch Petroleum Corporation, ${ }^{35}$ the US Supreme Court rejected jurisdiction based on a similar set of facts. Noting that the United Kingdom (UK) differs from the US with 'regard to the nature and strength of the presumption against extraterritorial jurisdiction', Blanco and Pontin review the UK jurisdictional rules and ultimately conclude that 'the English approach to allowing jurisdiction where the case "can be more suitably heard for the interests of all parties and the ends of justice" is a potentially valuable, albeit unilateral, development in transnational environmental law litigation' ${ }^{36}$

Through their nuanced look at English jurisdictional rules in the context of nuisance law, the authors highlight not only the challenges and opportunities available in the UK domestic courts for litigating claims where the harm is extraterritorial, but also the growing importance of thinking through such jurisdictional puzzles as the nature and scale of industrial pollution grows worldwide. As Blanco and Pontin emphasize, the choice of jurisdiction hinges not only on the remedies available, the opportunities for accessing justice and the likelihood of success, but also on 'whether litigation can proceed or not at all'. 37

Complementing the efforts by Green and Auld to unpack the role of private authority in complex environmental regimes, Blanco and Pontin demonstrate how private international environmental law is 'coming out of the shadow of its public international law counterpart in an arrangement that is complementary rather than mutually exclusive'. ${ }^{38}$

\section{THE ROLE OF MARKET-BASED MECHANISMS IN A TRANSNATIONAL WORLD}

Within and across domestic, transnational, and international environmental regimes, one persistent trend is the rise of market-based mechanisms as go-to tools for achieving environmental goals. This trend dates back to the mid-2000s with the embrace, in the Kyoto Protocol to the United Nations Framework Convention on Climate Change, ${ }^{39}$ of the flexibility mechanisms, and the move towards recognizing ecosystem services and developing new tools such as Payments for Ecosystem Services (PES) and offsets. Since that time, the use of market-based mechanisms has proliferated at every level and across conventional and hybrid systems of governance. Despite the growth in market-based mechanisms, questions of shape,

\footnotetext{
34 Ibid., p. 287.

35133 S. Ct. 1659 (2013).

36 Blanco \& Pontin, n. 33 above, p. 288, quoting Spiliada Maritime Corp. v. Cansulex Ltd [1987] AC 460 .

37 Blanco \& Pontin, n. 33 above, p. 307.

38 Ibid., p. 308.

39 Kyoto (Japan), 11 Dec. 1997, in force 16 Feb. 2005, available at: http://unfccc.int/resource/docs/ convkp/kpeng.pdf.
} 
function and fairness continue to plague their use in contexts ranging from the EU Emissions Trading Scheme to the mangrove forests in Bangladesh. In their articles, Jona Razzaque and Celeste Black explore the range of regulatory, economic, tax, and equity challenges involved in developing sustainable market-based mechanisms.

In her contribution, Razzaque ${ }^{40}$ offers a thoughtful analysis of the effectiveness and equity-based challenges inherent in efforts to use market-based instruments to facilitate sustainable development. Focusing on efforts to preserve the mangrove reserve forest of the Sundarbans in Bangladesh by using payments for forest ecosystem services, Razzaque carefully unpacks the economic, equity, and governance challenges that complicate efforts to use market-based mechanisms effectively in a biodiversity rich but economically poor area of Bangladesh.

In taking on the problem-laden question of how to effectively develop a PES system for forest services 'that were previously free', Razzaque cautions that the 'PES concept has the potential for better forest ecosystem management but it presents dangers and social costs unless carefully implemented and monitored inside an equitable and participatory system, inclusive of different types of actor, ${ }^{41}$ To this end, she emphasizes the importance of establishing clear sets of rights and obligations and notes that '[e]ffective forest rights allocation would benefit communities, reduce social conflict, and promote environmental protection and awareness' ${ }^{42}$ However, a failure to establish clear systems of rights and land ownership would undermine the effectiveness of the PES system and create significant social costs.

In chronicling efforts to implement a PES system in the Sundarbans, Razzaque highlights the extent to which governance deficiencies impede efforts to use marketbased systems effectively. Exploring future avenues for development, she looks to various transnational systems of forest governance, including World Bank initiatives and REDD+ ${ }^{43}$ to consider how regional efforts to develop PES schemes could be coupled with other systems of transnational governance to advance sustainable development goals.

Ultimately, Razzaque concludes that there is a substantial 'divergence between developed countries' enthusiasm for market-based regulation and safeguards, and the ability of developing countries to deliver such strategies effectively', ${ }^{44}$ and that the reasons for this divergence need to be better understood in order to develop PES schemes that provide environmental and social benefits.

In contrast to Razzaque, who explores the structural and social nuances of developing a PES system in a unique environment located in a rural area of Bangladesh, Black's contribution ${ }^{45}$ zooms out to offer critical insight into the

40 J. Razzaque, 'Payments for Ecosystem Services in Sustainable Mangrove Forest Management in Bangladesh' (2017) 6(2) Transnational Environmental Law, pp. 309-33.

41 Ibid., p. 317.

42 Ibid.

43 See UN REDD Programme, http://www.un-redd.org.

44 Razzaque, n. 40 above, p. 332.

45 C.M. Black, 'Taxation of Cross-Border Transfers of Carbon Emission Allowances under Linked Emissions Trading Schemes' (2017) 6(2) Transnational Environmental Law, pp. 335-61. 
important tax questions that should inform the development of emissions trading systems (ETSs).

In the absence of a top-down global ETS, Black offers an exhaustive analysis of the underexplored relationship between the efficiency of ETSs and the jurisdictional taxation schemes that determine how and when emissions allowances are taxed. Black meticulously documents how, in the context of cross-border emissions trading, the taxation regimes of the participating jurisdictions can influence the efficiency and, thus, the effectiveness of ETSs, with a specific focus on the potential for timing differences and double taxation. Having identified the importance of tax regimes to the functioning of ETSs, Black explores 'potential instances of differentiated tax treatment, which could feed into any future modelling of cost efficiency impacts', ${ }^{46}$ and offers a set of 'Base Case rules' that she then uses to analyze the erstwhile plans for an Australian ETS and a set of hypothetical trading scenarios involving the intersection of both domestic and international systems of law.

Black's ultimate goal in this article is to analyze the taxation consequences of different ETS cross-border transactions in order thereby to identify the strengths and weaknesses of current taxation regimes and provide valuable information to law and policymakers seeking to refine or develop ETSs. At a very basic level, Black's article reminds us, as did Turner's article, ${ }^{47}$ that in order to obtain a full picture of evolving systems of transnational environmental governance, including cooperative marketbased mechanisms, sometimes it is necessary to zoom out and take a macro-level look that reveals not only the complex drivers of environmental change, but also the different areas of law that intersect and impact upon the success and sustainability of different governance approaches.

\section{THE PRESENT AND FUTURE OF SMALL CETACEANS MANAGEMENT}

In the final contribution to this issue of TEL, Ed Couzens ${ }^{48}$ analyzes recent developments in the International Whaling Commission (IWC) with respect to the regulation of small cetaceans.

Couzens' commentary moves the focus away from theoretical examinations of transnational environmental law in flux, and the role of market mechanisms therein, to explore the role of traditional state-based institutions of public international law in addressing a long-standing but unresolved conservation challenge. The underlying challenge he highlights is the continued lack of governance over small cetaceans under the international whaling regime. ${ }^{49}$ While the issue of small cetacean management has been raised frequently in the IWC, very little has been done to facilitate new or

46 Ibid., p. 337.

47 Turner, n. 24 above.

48 E. Couzens, 'Size Still Matters, Although It Shouldn't: The Debate on Small Cetaceans, IWC 65, and Monaco's Resolution on Highly Migratory Cetaceans' (2017) 6(2) Transnational Environmental Law, pp. 363-74.

49 Ibid., pp. 363-4. 
enhanced management efforts. The IWC - which many consider 'the appropriate management authority' for small cetaceans - has 'effectively and definitively accepted jurisdiction over only a mere 15 or so species, leaving about 70 species unregulated by any international authority with global scope' ${ }^{50}$

Couzens offers an insightful overview of the history of efforts to bring small cetacean management into the fold of the IWC, culminating in the most recent efforts by Monaco to pass a resolution that would give contracting parties to the International Convention on the Regulation of Whaling (ICRW) ${ }^{51}$ a mandate to begin debating the future of small cetacean management. The Resolution, which was successfully passed in 2014, ${ }^{52}$ notes the highly migratory nature of all marine cetacean species, the need for international cooperation, and the need to coordinate coastal and High Seas conservation efforts. However, the Resolution also notes that the IWC alone cannot solve the problem and that more and greater cooperation and collaboration are needed.

Despite the successful adoption of the Resolution and subsequent efforts to integrate discussion on small cetacean management into other relevant international forums, small cetaceans remain at the edge of existing international institutions, leaving their future in jeopardy.

Couzens' commentary reminds us of the important role that fragmented, issuespecific regimes have played in global environmental law and management, while underlining the limitations of these institutions, particularly when confronting an issue that stretches or exceeds the original mandate of the regime. Despite the longstanding and ongoing discussions on the management of small cetaceans by the IWC, the issue remains contentious, evades resolution, and is unlikely to be resolved soon. Noting that the 'nature of international legal process is such that radical change is difficult to achieve quickly', and that IWC negotiations are characterized by 'acrimony' and 'emotional' debates, Couzens calls on contracting governments to 'proceed with caution' in order to raise awareness and support for more effective conservation of small cetaceans. ${ }^{53}$

\section{CONCLUSION}

In a terrain characterized by destabilizing trends of rapid environmental change, slow evolution of public international law institutions, and political shocks, the role and importance of transnational environmental law continues to grow. Defying traditional understandings of law, regulation, and governance, the evolving sphere of transnational environmental law requires us to rethink everything from fundamental questions such as 'what is law' and 'how does it operate', to more instrumental questions such as 'how we can harness emerging systems to better protect life in all its forms, from highly migratory species to rare mangrove

$50 \quad$ Ibid., p. 364.

51 Washington, DC (US), 2 Dec. 1946, in force 10 Nov. 1948, available at: https://iwc.int/convention.

52 Resolution 2014-2 (Resolution on Highly Migratory Cetaceans), available at: https:/iwc.int/ resolutions.

53 Couzens, n. 48 above, p. 374. 
ecosystems'. In keeping with TEL's mission to advance understanding of and scholarly dialogue on emerging issues in transnational environmental law, the contributions to this issue offer rich insight into the theoretical and practical dilemmas that underlie the evolution of transnational environmental law, and provide reason for optimism moving forward.

\section{TEL EDITORIAL BOARD DEVELOPMENTS}

In this final paragraph, we wish to extend our great appreciation and thanks to Jolene Lin, as she steps down from the Editorial Board. As a member of the TEL team since the journal's launch, we thank her for her support during TEL's foundational period, and wish her the very best in all her future endeavours. As Jolene steps down, we are delighted to welcome Josephine van Zeben as a new member of TEL's Editorial Board.

On the Assistant Editorial team, it is with sadness and gratitude that we say goodbye to Megan Bowman, while we are excited to welcome Alexia Staker and Aaron Wu as new Assistant Editors. We look forward to many more years of fruitful collaboration.

Editors-in-Chief Thijs Etty Veerle Heyvaert

Editors Cinnamon Carlarne

Dan Farber Bruce Huber Josephine van Zeben 